\title{
Application of the continuous autotransfusion system (CATS) to prevent transfusion-related hyperkalemia following hyperkalemic cardiac arrest in an infant -A case report-
}

\author{
Hye-Min Sohn, Yong-Hee Park, Hyo-Jin Byon, Jin-Tae Kim, Hee-Soo Kim, and Chong Sung Kim \\ Department of Anesthesiology and Pain Medicine, College of Medicine, Seoul National University, Seoul, Korea
}

Transfusion-induced hyperkalemia can lead to cardiac arrest, especially when the patient rapidly receives a large amount of red blood cells (RBCs), previously stored for a long period of time, irradiated or both. We report on a case of application of the Continuous AutoTransfusion System (CATS) to wash RBCs, in order to lower the high potassium $\left(\mathrm{K}^{+}\right)$level in the packed RBCs unit, during massive transfusion following transfusion-induced hyperkalemic cardiac arrest. After the washing process using CATS, there was no more electrocardiographic abnormality or cardiac arrest due to hyperkalemia. This case emphasizes the potential risk to develop transfusion-related hyperkalemic cardiac arrest, during massive transfusion of irradiated, pre-stored RBCs. CATS can be effectively used to lower the $\mathrm{K}^{+}$ concentration in the packed RBCs unit, especially when the risk of transfusion-induced hyperkalemia is high. (Korean J Anesthesiol 2012; 62: 281-284)

Key Words: Autologous, Blood transfusion, Cardiac arrest, Hyperkalemia, Massive transfusion.

We report on a case of application of the Continuous AutoTransfusion System (CATS, Fresenius AG, Bad Homburg, Germany) to wash RBCs, in order to lower the high potassium $\left(\mathrm{K}^{+}\right)$level in the packed RBCs unit, during massive transfusion following transfusion-induced hyperkalemic cardiac arrest.

\section{Case Report}

A 1-month-old, $3.1 \mathrm{~kg}$, male infant was scheduled for surgery due to huge hemorrhagic mass in the left posterior fossa, which extended to the left upper neck through the jugular foramen (Fig. 1). Before the intervention, the patient received mechanical respiratory care in the pediatric ICU. The oxygen saturation $\left(\mathrm{SpO}_{2}\right)$ was $98 \%$ on $\mathrm{F}_{\mathrm{I}} \mathrm{O}_{2} 0.4$, under mechanical ventilation. The serum hematocrit was $43 \%$ and the serum $\mathrm{K}^{+}$was $3.7 \mathrm{mM} / \mathrm{L}$.

Prior to induction of anesthesia, the vital signs were stable. After standard, non-invasive monitoring was applied, anesthesia was induced with atropine $0.06 \mathrm{mg}$ and thiopental $18 \mathrm{mg}$.

Received: July 13, 2011. Revised: September 24, 2011. Accepted: October 5, 2011.

Corresponding author: Jin-Tae Kim, M.D., Department of Anesthesiology and Pain Medicine, College of Medicine, Seoul National University, 101, Daehak-ro, Jongno-gu, Seoul 110-744, Korea. Tel: 82-2-2072-3295, Fax: 82-2-747-5639, E-mail: kimjintae73@dreamwiz.com

(c) This is an open-access article distributed under the terms of the Creative Commons Attribution Non-Commercial License (http:// creativecommons.org/licenses/by-nc/3.0/), which permits unrestricted non-commercial use, distribution, and reproduction in any medium, provided the original work is properly cited. 
Manual ventilation was performed with sevoflurane 8 vol\% in $100 \%$ oxygen, and rocuronium $1.8 \mathrm{mg}$ was injected for muscle relaxation. The initial endotracheal tube was changed to reinforced endotracheal tube ID $3.0 \mathrm{~mm}$ and a 24-gauge catheter was placed in the left radial artery.

The double lumen 4-Fr central venous catheter was placed in the right subclavian vein. A forced-air warming blanket was used to maintain the normal temperature range. Anesthesia was maintained with inhalation of sevoflurane and intermittent boluses of fentanyl and rocuronium. The patient was placed into the prone position for surgical approach.

Although the amount of bleeding was not small, the patient's vital signs remained stable for the first two hours of surgery (systolic $\mathrm{BP} 70-90 \mathrm{mmHg}$, pulse rate $120-140 \mathrm{bpm}, \mathrm{SpO}_{2} 99 \%$, and temperature $36^{\circ} \mathrm{C}$ ). Blood laboratory tests were performed 30 minutes prior to the first cardiac arrest, as presented in Table

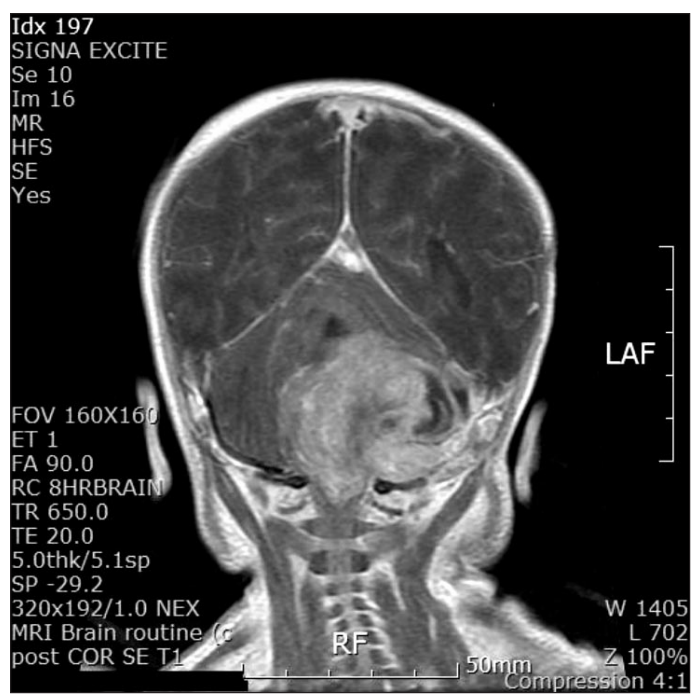

Fig. 1. Preoperative Brain MRI contrast-enhanced T1-weighted image showing huge hemorrhagic tumor in left posterior fossa extending to the left upper neck though jugular foramen.
1. During this period, volume replacement consisted of $350 \mathrm{ml}$ of $0.9 \%$ normal saline and 1 unit of non-irradiated RBCs (average unit volume $160 \mathrm{ml}$, hematocrit $70 \%)$. Calcium chloride $\left(\mathrm{CaCl}_{2}\right)$ was administered upon the result of the blood test.

After 1 pack of non-irradiated RBCs for a hematocrit of $25 \%$, the patient started to receive irradiated RBCs. The RBCs had been irradiated 5 days prior to transfusion. Meanwhile, the operative blood loss increased substantially. Blood loss was replaced by rapid intravenous administration of the RBCs. Shortly after injection of the RBCs, the patient's heart rate slowed to $60 \mathrm{bpm}$. This episode was accompanied by morphological changes seen on the ECG. The QRS interval was widened, tall peaked T-waves were observed on V1-V6 leads and the ECG became isoelectric. The patient's peripheral pulse was impalpable. The anesthesiologists commenced external chest compressions with the 2 thumb-encircling technique, because the child was placed in the prone position. An adequate cardiac output was achieved with this technique, as evidenced via oximetry, arterial pressure and capnography readings. Before the cardiac arrest, approximately $80 \mathrm{ml}$ of irradiated RBCs had been transfused for 10 minutes.

Following the cardiac arrest, the hematocrit was $38 \%$, while the serum $\mathrm{K}^{+}$was increased to $14.2 \mathrm{mM} / \mathrm{L}$.

Thus, transfusion was stopped on the suspicion of transfusion-induced hyperkalemia. We infused the mixture of 10 units of regular insulin and $50 \mathrm{ml}$ of $50 \%$ dextrose. Several doses of epinephrine $10 \mathrm{mcg}$, atropine $0.1 \mathrm{mg}$, and $\mathrm{CaCl}_{2} 30 \mathrm{mg}$ were administered, with concomitant chest compressions.

Seven minutes after the cardiac arrest, the cardiac electrical activity was returned and BP was 70/40 mmHg. Ten minutes after recovery of spontaneous circulation, an arterial blood sample was tested, and the $\mathrm{K}^{+}$level was found significantly decreased to $6.8 \mathrm{mM} / \mathrm{L}$. At this time, other laboratory data were also quite close to the normal limits, as shown in Table 1.

Further massive transfusion would have resulted in a potentially fatal, further increase in the serum $\mathrm{K}^{+}$level. The patient

Table 1. Laboratory Results of the Blood During the Operation and the Processed RBCs

\begin{tabular}{|c|c|c|c|c|c|c|c|}
\hline Time & $-2 \mathrm{hr}$ & $-30 \min$ & 0 (arrest) & $+10 \min$ & $+3 \mathrm{hr}$ & $+6 \mathrm{hr}$ & Processed RBCs \\
\hline $\mathrm{pH}$ & 7.38 & 7.27 & 6.95 & 7.07 & 6.98 & 6.85 & $<6.80$ \\
\hline $\mathrm{PaCO}_{2}(\mathrm{mmHg})$ & 44 & 35 & 63 & 53 & 69 & 103 & 57 \\
\hline $\mathrm{PaO}_{2}(\mathrm{mmHg})$ & 99 & 99 & 49 & 297 & 144 & 60 & 52 \\
\hline $\mathrm{HCO}_{3}{ }^{-}(\mathrm{mM} / \mathrm{L})$ & 26.0 & 16.1 & 13.8 & 15.4 & 16.2 & 18.0 & - \\
\hline $\mathrm{BE}(\mathrm{mM} / \mathrm{L})$ & 0.9 & -10.8 & -18.3 & -14.7 & -15.4 & -15.7 & - \\
\hline $\mathrm{Hb}(\mathrm{g} / \mathrm{dL})$ & 9.2 & 8.5 & 12.9 & 12.6 & 10.5 & 8.8 & 20.1 \\
\hline Hct (\%) & 27 & 25 & 38 & 37 & 31 & 26 & 59 \\
\hline $\mathrm{Na}^{+}(\mathrm{mM} / \mathrm{L})$ & 131 & 137 & 133 & 136 & 153 & 152 & 129 \\
\hline $\mathrm{K}^{+}(\mathrm{mM} / \mathrm{L})$ & 3.9 & 3.7 & 14.2 & 6.8 & 3.2 & 4.1 & 19.9 \\
\hline $\mathrm{Ca}^{2+}(\mathrm{mM} / \mathrm{L})$ & 1.18 & 1.14 & 0.39 & 1.13 & 0.68 & 1.70 & - \\
\hline
\end{tabular}

At the time of 0, isoelectric ECG. $\pm \mathrm{N}$ time: $\mathrm{N}$ minutes before and after arrest time. BE: base-excess, Hb: hemoglobin, Hct: hematocrit. $-:$ unmeasurable. Data at $+3 \mathrm{hr}$ and $+6 \mathrm{hr}$ were obtained while processing of RBCs using CATS. 
continued to bleed, and transfusion was absolutely mandatory.

Therefore, we decided to wash these RBCs before transfusion by using a CATS which was readily available in the operating room.

During the operation, the patient received 27 more units of blood bank RBCs; each was processed with $0.9 \%$ normal saline by the CATS before transfusion, but the cell saver device was not used to salvage shed blood. The packed RBCs were filtered, washed, and then reinfused to the patient. Utilizing a transfusion set, the packed RBCs were prepared and were mixed with an anticoagulation solution (25,000 iu of heparin per each $1 \mathrm{~L}$ normal saline) in the reservoir. When a volume has been collected enough to fill the wash bowl, the processing began. The washing phase removed cellular debris, plasma free hemoglobin, anticoagulant solution, activated clotting factors, any plasma bound antibiotics, intracellular enzymes, plasma, platelets, and white cells. When the washing phase has been terminated, the device pumped the blood into the reinfusion bag and stopped when the bowl is emptied. After using CATS, there was no more electrocardiographic abnormality or cardiac arrest due to transfusion-related hyperkalemia.

While waiting for non-irradiated RBCs were ready at the blood bank, we started the first washing process with irradiated RBCs. But, transfusion was performed with non-irradiated RBCs after the preparation of non-irradiated RBCs.

On the occasion of arrest, esophageal temperature fell to $34^{\circ} \mathrm{C}$. Accordingly, Level 1 rapid infusion (SIMS Level 1, Inc., Rockland, MA) system was installed that ensures blood products are delivered at the proper temperature.

Table 1 shows the biochemistry of the blood during the operation. The processed RBCs were also tested and revealed $\mathrm{K}^{+}$concentration of $19.9 \mathrm{mM} / \mathrm{L}$ and hematocrit $59 \%$.

However, at a certain point, the bleeding was uncontrollable. The blood biochemistry at this time is shown in Table 1, as results at ' 6 hr' following the cardiac arrest. The surgeon decided to stop the mass excision and bleeding control. After skin closure, the patient was transferred to the pediatric ICU and expired at the ICU.

During operation, the estimated blood loss was 9,000 $\mathrm{ml}$. Infused fluids consisted of normal saline $750 \mathrm{ml}$, HES $640 \mathrm{ml}$, RBCs 28 units, fresh frozen plasma 21 units, platelet concentrate 9 units, and cryoprecipitate 1 unit.

\section{Discussion}

The pathogenesis of hyperkalemia-induced cardiac arrest during massive RBCs transfusion is complex, and it depends on the quality of RBCs, the patient, and administration factors. The $\mathrm{K}^{+}$concentration in the stored $\mathrm{RBC}$ unit may be one of the most important factors. Serious patient condition, such as low cardiac output, may increase the $\mathrm{K}^{+}$level in the coronary artery during RBCs transfusion. It may also be affected by other patient factors, such as hypocalcemia, hypothermia and acidosis [1]. Finally, the amount, the speed, and the route of transfusion are all associated with hyperkalemia-induced cardiac arrest. In our case, rapid transfusion of RBCs was urgently required, and $80 \mathrm{ml}$ of blood was injected through the central line. Rapid administration through the central venous access may deliver more concentrated $\mathrm{K}^{+}$loads to the coronary circulation than the peripheral venous access, and this could have contributed to provoking cardiac arrest [2].

We would like to pay more attention to the quality of the RBCs, which had been irradiated 5 days prior to transfusion. Although irradiation policies vary in different hospitals, the time between irradiation and transfusion should be minimized, particularly in neonates or pediatric patients. Irradiation is thought to increase the damage to the membrane bound ionic pumps, leading to increased leak of $\mathrm{K}^{+}$into the extracellular space [1]. Therefore, it has been demonstrated that irradiated RBCs have significantly higher extracellular $\mathrm{K}^{+}$levels than non-irradiated units [3]. Similarly, it has been shown that the increase in the $\mathrm{K}^{+}$level was more significant in RBCs stored for longer periods of time, prior to transfusion [4]. Therefore, both the British Committee for Standards in Haematology Blood Transfusion Task Force and the Australian \& New Zealand Society of Blood Transfusion suggested the following guidelines:

1. Red cells may be irradiated at any time up to 14 days after collection, and thereafter stored for a further 14 days from irradiation. 2. Where the patient is at particular risk from hyperkalemia, it is recommended that red cells be transfused within 24 hours of irradiation [5].

Washing of the RBCs may also increase the $\mathrm{K}^{+}$levels. However, it is unlikely that a unit of RBCs would have a $\mathrm{K}^{+}$concentration higher than $5 \mathrm{mM} / \mathrm{L}$ after washing, during 6 hours of storage at $4^{\circ} \mathrm{C}$ if the cells were not irradiated, and for 3 hours if the cells were irradiated [6]. In our case, we transfused the postwashing RBCs within 3 hours of the washing process.

It has been demonstrated that processing of stored RBCs with CATS effectively removes cellular products and metabolites, while maintaining the physiologic electrolyte range [7]. Similarly, the washing of the RBCs results in very low levels of residual $\mathrm{K}^{+}$[8]. The CATS autotransfusion system has been documented for a mean $\mathrm{K}^{+}$elimination rate of $97.3 \%$ [9]. This rate may vary, depending on the washing devices and modes. There are two representative operational modes for this system, depending on the adequate volume to fill the bowl and the speed of processing. Compared with the quality mode, the emergency mode is characterized by faster processing, thereby consuming less washing solution. According to a previous 
article, quality mode CATS reduced the median load of $\mathrm{K}^{+}$ to $92 \%$ of the baseline, whereas the emergency mode CATS reduced it to only $70 \%$ of that [10].

Although we followed the guidelines suggested in several previous studies, our case showed a higher level of $\mathrm{K}^{+}$than expected. To evaluate the quality of the washed RBCs, we measured the $\mathrm{K}^{+}$level after processing with the CATS and the concentration was very high, i.e. $19.9 \mathrm{mM} / \mathrm{L}$. We could not measure the $\mathrm{K}^{+}$concentration of the packed RBCs before processing. We used the Gem Premier 3000 system to check for the parameters, and the range of $\mathrm{K}^{+}$concentration that could be displayed with this device was from 0.1 to $20.0 \mathrm{mM}$ / L. Therefore, we did not know the exact value. Nevertheless, according to several previous studies, it is assumed that the $\mathrm{K}^{+}$ level might be, on average, $40 \mathrm{mM} / \mathrm{L}$ in non-irradiated RBCs [9] and $60 \mathrm{mM} / \mathrm{L}$ in the irradiated units $[11,12]$. In our case, supposing pre-processing value of $60 \mathrm{mM} / \mathrm{L}, \mathrm{K}^{+}$was reduced only $67 \%$ after processing.

In this presented case, we could suggested 3 possible reasons which may have contributed to the relatively high level of $\mathrm{K}^{+}$in the washed RBCs. First, we used the emergency mode not the quality mode, because we had to install the device immediately after reversing the cardiac arrest. Second, we used relatively old blood and there was a delay of 5 days in the use of these units after radiation; these factors could both lead to high $\mathrm{K}^{+}$concentration in the prewashed RBCs unit. It has been shown that, if the blood product was more than 17 days old, the reduction in the $\mathrm{K}^{+}$level after washing it was less efficient than after washing fresh RBC units [8]. Third, if the RBCs were transfused as soon as processed and not stored in the collecting bottle, the $\mathrm{K}^{+}$concentration could be lower, because there might be an increase of hemolysis in the washed RBCs while stored at room temperature, as previously reported [6]. Hence, to strengthen the merits of CATS, using quality mode rather than emergency mode is recommended, and fresh RBCs are always preferable, especially in infants. Washing should be done just before whenever needed, so that the RBCs would not be left at room temperature for a long time.

One thing to consider is heparin. Although the packed RBCs were mixed with a large amount of heparin in the reservoir, the ratios of residual heparin in washed red cells transfused to neonatal or pediatric patients are extremely low [13]. Therefore, when properly processed, autotransfusion does not provoke bleeding and can be used safely with neonates and pediatric patients, without concern regarding the residual heparin [14].

In conclusion, CATS can be used for decreasing the $\mathrm{K}^{+}$level of the RBCs before transfusion, particularly when clinically significant hyperkalemia is anticipated in neonates and infants, and the risk of hyperkalemic cardiac arrest is high.

\section{References}

1. Smith HM, Farrow SJ, Ackerman JD, Stubbs JR, Sprung J. Cardiac arrests associated with hyperkalemia during red blood cell transfusion: a case series. Anesth Analg 2008; 106: 1062-9.

2. Sloan SR. Neonatal transfusion review. Paediatr Anaesth 2011; 21: 25-30.

3. Dinning G, Doughty RW, Reid MM, Lloyd HL. Potassium concentrations in irradiated blood. BMJ 1991; 303: 1110.

4. Duguid J, Cunningham J, Pender N. Potassium concentrations in irradiated blood. BMJ 1992; 304: 120.

5. Treleaven J, Gennery A, Marsh J, Norfolk D, Page L, Parker A, et al. Guidelines on the use of irradiated blood components prepared by the British Committee for Standards in Haematology blood transfusion task force. Br J Haematol 2011; 152: 35-51.

6. Weiskopf RB, Schnapp S, Rouine-Rapp K, Bostrom A, Toy P. Extracellular potassium concentraions in red blood cell suspensions after irradiation and washing. Transfusion 2005; 45: 1295-301.

7. O'Leary MF, Szklarski P, Klein TM, Young PP. Hemolysis of red blood cells after cell washing with different automated technologies: clinical implications in a neonatal cardiac surgery population. Transfusion 2011; 51: 955-60

8. Bansal I, Calhoun BW, Joseph C, Pothiawala M, Baron BW. A comparative study of reducing the extracellular potassium concentration in red blood cells by washing and by reduction of additive solution. Transfusion 2007; 47: 248-50.

9. Knichwitz G, Zahl M, Van Aken H, Semjonow A, Booke M. Intraoperative washing of long-stored packed red blood cells by using an autotransfusion device prevents hyperkalemia. Anesth Analg 2002; 95: 324-5.

10. Westphal-Varghese B, Erren M, Westphal M, Van Aken H, Ertmer C, Lange M, et al. Processing of stored packed red blood cells using autotransfusion devices decreases potassium and microaggregates: a prospective, randomized, single-blinded in vitro study. Transfus Med 2007; 17: 89-95.

11. Baz EM, Kanazi GE, Mahfouz RA, Obeid MY. An unusual case of hyperkalaemia-induced cardiac arrest in a paediatric patient during transfusion of a 'fresh' 6-day-old blood unit. Transfus Med 2002; 12: 383-6.

12. Strauss RG. Data-driven blood banking practices for neonatal RBC transfusions. Transfusion 2000; 40: 1528-40.

13. Sistino JJ, Owitz D, Mongero LB. Heparin washout in the pediatric Cell Saver bowl. J Extra Corpor Technol 1992; 24: 94-6.

14. Kling D, Börner U, von Bormann B, Hempelmann G. Heparin elimination and free hemoglobin following cell separation and washing of autologous blood with Cell Saver 4. Anasth Intensivther Notfallmed 1988; 23: 88-90. 